\title{
Serum Cortisol and BMI in Chronic Diseases and Increased Early Cardiovascular Diseases
}

\author{
Ekhlas Abdallah Hassan
}

Wafaa Sh. Al-Zuhairi

\begin{abstract}
Maryam A. Ahmed
Department of Chemistry, College of Science, University of Diyala, Baquba, Diyala, Iraq

E-mail: ekhlaschem@yahoo.com
\end{abstract}

Received 9/10/2015

Accepted 20/12/2015

\section{(i) $(9)$}

NoDerivatives 4.0 International Licens

\begin{abstract}
:
The purpose of this study was to examine the role of cortisol, and it is related to BMI in the chronic diseases which may increase early cardiovascular disease (CVD) in old Iraqi. The subjects were 116 adults, aged 51-71 years. Body Mass Index (BMI), Waist Circumferences (WC) and Waist Hip Ratio (WHR) were used as a measure of adiposity. Investigation showed highly significant difference between patients in BMI ranges, most of male were in an obese weight range (48.5\%), as well in women. There were no significant correlations between serum cortisol concentration and age both gender groups. While there were highly significant correlations between cortisol level and BMI, waist, and WHR (except in female subjects), also there were highly significant correlations between cortisol level and SBP,DBP (mmHg)only in male. In both groups, total cholesterol concentration, FBS, and A1C were significantly correlated with serum cortisol. Negatively correlated has been observed between serum cortisol and HDL-C in men but not in women. In men, the results of cortisol with CV risk factors (dyslipidemia, D.M, hypertension, at least 2 risk factors and three risk factors) show significant differences ( $>0.0)$.

In summary, there is a major association between cortisol levels, obese, and chronic diseases. These conclusions promote the hypothesis that the opposing effect of adiposity on the chronic diseases might be mediated by cortisol. This association could cause early development of cardiovascular diseases even in males.
\end{abstract}

Key words: Cortisol, Body Mass Index, Chronic Diseases, Cardiovascular Disease.

\section{Introduction}

Obesity is the main major factor that is associated with other illnesses such as heart disease, diabetes mellitus, and high BP, which are considered the top global health issues. Unnecessary accumulation of body fat can characterize obesity, which is a multifaceted pathophysiological condition. Because of two combination factors; environmental and genetic, obesity remains a chronic disorder. These factors are determined balance 
between caloric intake and spending. A major increased risk's factor of illness and mortality is associated with excess body fat [1]. In addition, regardless of weight, high body fat is correlated with a high occur of CVD and its factors of risk [2]. Even if body fat assessments are available currently, the optimal body fat limits which replicate obesityassociated CVD are ambiguous [3- 7]. Many studies have discovered that cortisol high levels' are one causal factor to storage, "visceral" abdominal body fat, of fat. Particularly, fat is unhealthy for heart disease [8]. Besides, the relation between obesity and plasma cortisol are more complicated, because cortisol increased metabolic clearance rate's which is associated with obesity, that tends to lower the levels plasma cortisol in spite of enhanced rate of cortisol production. A study shows that effects in predicting risk factors of cardiovascular of raised plasma cortisol and obesity in people with chronic diseases are additive and independent $[9,10] \quad$ Metabolic syndrome, hypertension, and diabetes are examples of obesity-related disorder, where the major causal factor is obesity [11]. We will not consider metabolic syndrome from the CVD factors in this study, since it has several definitions, unclear pathophysiology and remain a source of controversy in medical research [12]. The current study was to answer if elevated cortisol is associated with increased BMI and early CVD in Iraqi adults.

\section{Materials and Methods:}

This study has been carried out at the consultative clinic in Baquba, for the period November 2014. The study included (90) patients (40 females and 50 males) with age range (51-70) year.26 Iraqi control subjects comparable to patients in respect to age (55-70 year) and gender (12 females and 14 males), were included in the study.

\section{Assessment of Cardiovascular Risk Factors}

Waist and hip circumferences were measured by using a tape measure, to assess the fat distribution. A waist circumference was measured at the level of umbilicus while hip circumferences were measured at the maximum protuberance of the buttocks [13]. The waist hip ratio was calculated by dividing waist circumference in centimeters by the hip circumference in centimeters [14]. The cutoff value for acceptable WHR that is used as an indicator of central obesity in male and female were 0.95 and 0.80 respectively $[15,16]$. Body mass index was calculated for each subject using the following equation: $\mathrm{BMI}=$ Weight $(\mathrm{Kg})$ / height ${ }^{2}\left(\mathrm{~m}^{2}\right)$, and blood pressure was measured indirectly by auscultation (listening to sounds) described in 1902 by Russian physician N.S.Korotkoff, using a stethoscope and sphygmomanometer (SKMINIATUR300B- Germany) consisting of a blood pressure cuff and a mercury column pressure gauge. Both systolic and diastolic blood pressure were recorded in $\mathrm{mm} \mathrm{Hg}$. Hypertension was defined as a systolic blood pressure_140 $\mathrm{mm} \mathrm{Hg}$, a diastolic blood pressure _90 $\mathrm{mm} \mathrm{Hg}$, or treatment of hypertension [17].An 8-hrs fasting blood sample was collected from each subject and prepared for diagnosis of dyslipidemia and diabetes mellitus. Total cholesterol (TC) and triglyceride concentrations were measured by using enzymatic methods. HDL cholesterol was measured after precipitation of apolipoprotein B-containing lipoproteins with sodium phosphor tungstate and magnesium chloride. LDL-cholesterol concentrations were calculated by using the Friedewald formula. Fasting serum glucose (FSG) was measured by using the glucose oxidase method. Glycated hemoglobin (HbA1C) was measured by liquid 
chromatography. Dyslipidemia was defined as TC $>240 \mathrm{mg} / \mathrm{dL}$ and/or HDL cholesterol $<40 \quad \mathrm{mg} / \mathrm{dL} \quad$ and/or triglyceride $>150 \mathrm{mg} / \mathrm{dL}$ or treatment of dyslipidemia [18,19]. Diabetes mellitus was defined as FSG $>126 \mathrm{mg} / \mathrm{dL}$ and $\mathrm{Hb} \mathrm{A} 1 \mathrm{C}>6.5 \%$ or treatment of the disease $[19,20]$.An individual was considered a patient when they had _1 of 3 CVD risk factors, such as hypertension, dyslipidemia, and type 2 diabetes mellitus.

\section{Statistical Analysis}

Data were analyzed using the computer facility with available statistical packages of SPSS 11.5 (statistical packages for social sciences-version 11.5). The statistical significance of difference in mean of a normally distributed quantitative variable between 2 groups was assessed by independent samples t-test. In a first analysis, we compared male and female patient groups with different biochemical parameters (plasma glucose, HbA1c, total cholesterol, HDL-cholesterol, systolic and diastolic blood pressures,), with additional covariates [age, gender, body mass index (BMI), WC, and WHR] and in a second analysis we studied the distribution of patients according to BMI. Then we measured the concentration of serum cortisol in different patients depending on BMI, and compared it with healthy men. Also we measured the concentration of serum cortisol in different patients depending on BMI, A level of 0.05, 0.01 and 0.001 was used to determine the statistical significance.

\section{Results and Discussion:}

The commonness risk factors of cardiovascular, including high cholesterol, smoking, and untreated hypertension, have fallen significantly since the 1960s, however, prevalence of overweight and particularly obesity continues to rise and become new risk factor. Obesity may become the most common health problem of the $21^{\text {st }}$ century.It is major driving force responsible for the increased prevalence of cardiovascular disease in the developed world. This chronic noncommunicable disease is therefore a major contributor to the global burden of disease and disability associated with numerous conditions such as heart disease, stroke, hypertension, dyslipidemia, type 2 diabetes mellitus, and numerous cancers (endometrial, breast, prostate, and colon). Table (1) shows the clinical characteristics of the study patients. We found that the clinical characteristic of 68 males were similar to female in terms of $\mathrm{A}_{1} \mathrm{C}$, DBP(mmHg), BMI SBP(mmHg), Tri , FBS , TC, HDL-C, VLDL-C, LDL-C, and age. However, compering between male and female by main waist, we observed that male had elevated main WC and WHR than female and there was a significant difference. Our investigation agrees with the World Health Organization and the International Diabetes Federation [22]. 
The $2^{\text {nd }}$ National Conference of Chemistry

Table (1): Characteristics of study subjects

\begin{tabular}{|c|c|c|c|c|}
\hline Variable & whole & male & Female & $\mathrm{P}$ value \\
\hline $\mathrm{n}$ & 90 & 50 & 40 & \\
\hline Age (years) & $59.2 \pm 9.9$ & $60.8 \pm 9.5$ & $57.6 \pm 10.4$ & 0.12 \\
\hline \multicolumn{5}{|l|}{ Obesity measure } \\
\hline BMI & $30.3 \pm 4.4$ & $30.3 \pm 5.9$ & $29.4 \pm 5.6$ & NS \\
\hline Waist & $101.1 \pm 13.4$ & $105.8 \pm 12.3$ & $96.4 \pm 14.6$ & $\mathrm{P}<0.001$ \\
\hline WHR & 0.892 & 0.946 & 0.84 & $\mathrm{P}<0.001$ \\
\hline \multicolumn{5}{|c|}{ cardiovascular risk factors measure } \\
\hline \multicolumn{5}{|l|}{ 1-Hypertension } \\
\hline $\mathrm{SBP}(\mathrm{mmHg})$ & $132.7 \pm 10.7$ & $133.3 \pm 10.5$ & $132.0 \pm 10.7$ & 0.36 \\
\hline $\mathrm{DBP}(\mathrm{mmHg})$ & $76.4 \pm 8.05$ & $76.0 \pm 7.3$ & $74.8 \pm 8.8$ & 0.53 \\
\hline \multicolumn{5}{|l|}{ 2- dyslipidemia } \\
\hline TC & $228.05 \pm 51.45$ & $228.8 \pm 54.7$ & $227.3 \pm 48.2$ & NS \\
\hline HDL-C & & $45.4 \pm 21.1$ & $46.9 \pm 15$ & NS \\
\hline LDL-C & & $144.2 \pm 49.3$ & $144.6 \pm 46.8$ & NS \\
\hline VLDL-C & & $41.62 \pm 40.1$ & $41.42+32.2$ & NS \\
\hline Tri & & $208.1 \pm 20.1$ & $207.1 \pm 16.1$ & NS \\
\hline \multicolumn{5}{|l|}{ 3-Diabetes mellitus } \\
\hline FBS & & $155.2 \pm 35$ & $160.7 \pm 38.8$ & \\
\hline $\mathrm{A}_{1} \mathrm{C}$ & & $7.35 \pm 3.2$ & $7.72 \pm 2.1$ & NS \\
\hline
\end{tabular}

Significant difference using student's ttest for comparing between two independent means at 0.001levels of significances.

In Table (2) we notice that there was a highly significant difference $(\mathrm{P}<0.01)$ between patients in BMI ranges, most of male were in obese weight range (48.5\%). Also Table 2 show that there were significant difference $(\mathrm{P}<0.01)$ between women in BMI range. Our results are agree with the National Health and Nutrition Examination Survey, which points out that roughly $30 \%$ of adults were overweight in 20112012 and in compering to $19.3 \%$ in 2001. For example in 10 years, obesity is approximately increased to $30 \%$, which is major risk factor for heart disease, Type-2 diabetes, cancer, and stroke [23].

Table (2): Distribution of Patients According BMI $\left(\mathrm{Kg} / \mathrm{m}^{2}\right)$

\begin{tabular}{|c|c|c|c|}
\hline BMI & $\mathrm{N}$ & $\%$ & $\begin{array}{c}\text { Comparison of } \\
\text { significant by Kruskal- } \\
\text { Wallis Test } \\
\end{array}$ \\
\hline Men & & & \multirow{6}{*}{$P<0.01$} \\
\hline $18.5-24.9$ & 7 & $10.3 \%$ & \\
\hline $25-29.9$ & 16 & $29.4 \%$ & \\
\hline $\begin{array}{l}30-34.9 \\
\end{array}$ & 21 & $48.5 \%$ & \\
\hline $35-39.9$ & 6 & $11.8 \%$ & \\
\hline total & 50 & 100 & \\
\hline Women & & & \multirow{6}{*}{$\mathrm{P}<0.01$} \\
\hline $18.5-24.9$ & 4 & 8.3 & \\
\hline $25-29.9$ & 10 & 31.3 & \\
\hline $30-34.9$ & 23 & 54.2 & \\
\hline $35-39.9$ & 3 & 6.2 & \\
\hline total & 40 & 100 & \\
\hline
\end{tabular}

In Table (3) there were no significant correlations between serum cortisol concentration and age in both gender groups $(r=0.217, p>0.05), \quad(r=0.103$, $\mathrm{p}>0.05$ ) respectively. Though there were highly significant correlations between cortisol level and BMI ( $\mathrm{r}=0.882$, $\mathrm{p}<0.001), \mathrm{WC}(\mathrm{r}=0.659, \mathrm{p}<0.05)$, and WHR $(r=0.734, \mathrm{p}<0.05)$ also there were highly significant correlations between cortisol level and $\operatorname{SBP}(\mathrm{r}=0.386$, $\mathrm{p}<0.05), \quad \operatorname{DBP}(\mathrm{mmHg}) \quad(\mathrm{r}=\quad 0.392$, $\mathrm{p}<0.001)$ only in male. Our study has same result as Fraser study [23]. Moreover, Filipovsky reported that morning plasma cortisol concentration to be lower in normotensive, mainly in lean hypertensive subjects, than in hypertensive subject [24].

In the same way, Litchfield found that hypertensive patients have higher urinary free cortisol excretion rates. The rates were higher with high salt intake and higher in men than women [25].In both groups, $\mathrm{FBS}$ and $\mathrm{A}_{1} \mathrm{C}$ were significantly correlated with serum cortisol, because serum cortisol with smaller increases might contribute to anomalous glucose metabolism recognized to happen in metabolic abnormalities and subsequently type 2 diabetes" [26]. In addition, we got positive correlation between serum cortisol and cholesterol. Also, we got negative correlation between serum 
cortisol and HDL-C $(r=-0.480 \mathrm{p}<0.05)$ in men but not in women. A study done by Sadiqa et al shows that HDL cholesterol and cortisol had inverse relationship which survived stepwise multiple regression analysis and was significant in both women and men. Therefore, cortisol can affect peripheral cholesterol metabolism to change HDL cholesterol formation. Since, cardiovascular risk is intensely associated with lower level of HDL [27].

Table (3): Correlations between Serum Cortisol Concentration and Variable

\begin{tabular}{|c|c|c|}
\hline \multirow{2}{*}{ Variable } & \multicolumn{2}{|c|}{ Cortisol $(\mathbf{n g} / \mathbf{m l})$} \\
\cline { 2 - 3 } & Male & Female \\
\hline Age (years) & 0.217 & 0.133 \\
\hline BMI & $0.882^{* *}$ & 0.442 \\
\hline Waist & $0.659^{* *}$ & 0.258 \\
\hline WHR & $0.734^{*} *$ & 0.227 \\
\hline SBP(mmHg) & $0.386^{*}$ & 0.272 \\
\hline DBP(mmHg) & $0.392^{*}$ & 0.187 \\
\hline TC & $0.381^{*}$ & $0.140^{*}$ \\
\hline HDL-C & $-0.480^{*}$ & 0.137 \\
\hline FBS & $0.416193^{* *}$ & $0.481^{*}$ \\
\hline $\mathrm{A}_{1} \mathrm{C}$ & $0.303292^{*}$ & $0.386^{*}$ \\
\hline
\end{tabular}

*Correlation is significant at the 0.05 level

** Correlation is significant at the 0.01 level

The results of cortisol with $\mathrm{CV}$ risk factors (dyslipidema, D.M, hypertension, At least 2 risk factors and three risk factors) are shown in figures 1.Significant differences $(p>0.01)$ were obtained in BMI among any of the studied groups. A study by Reynolds reported that BMI had significant differences for people who have dyslipidemia or DM2. Which is same as our conclusion. There is a study showed that they got significant positive difference between BMI and hypertension [25], which is the same as our result. Also, we obtained that people, who have at least two risk factors (dyslipidema, DM2), have significant differences with BMI and this obtaining agrees with Oltmanns study [26]. Insulin resistance (IR) is enhanced by body fat accumulation and hyperlipidemia via impairing insulin signaling, increasing free fatty acid in portal blood vessels on one hand, "and by inhibiting key signaling proteins, indicating disturbances in glucose and lipid metabolism, and lead to cortisol secretion on the other hand" [27].

Also, we obtained that people, who have at least three risk factors (dyslipidema, DM2, and hypertention), have significant differences with BMI. Moreover, there is increasing proof that cardiovascular risk is contributed by cortisol, which is not only in Cushing syndrome, but more commonly, in male. Hypertension, dyslipidemia, obesity, insulinresistance, and hyperglycemia are all significant in this respect.

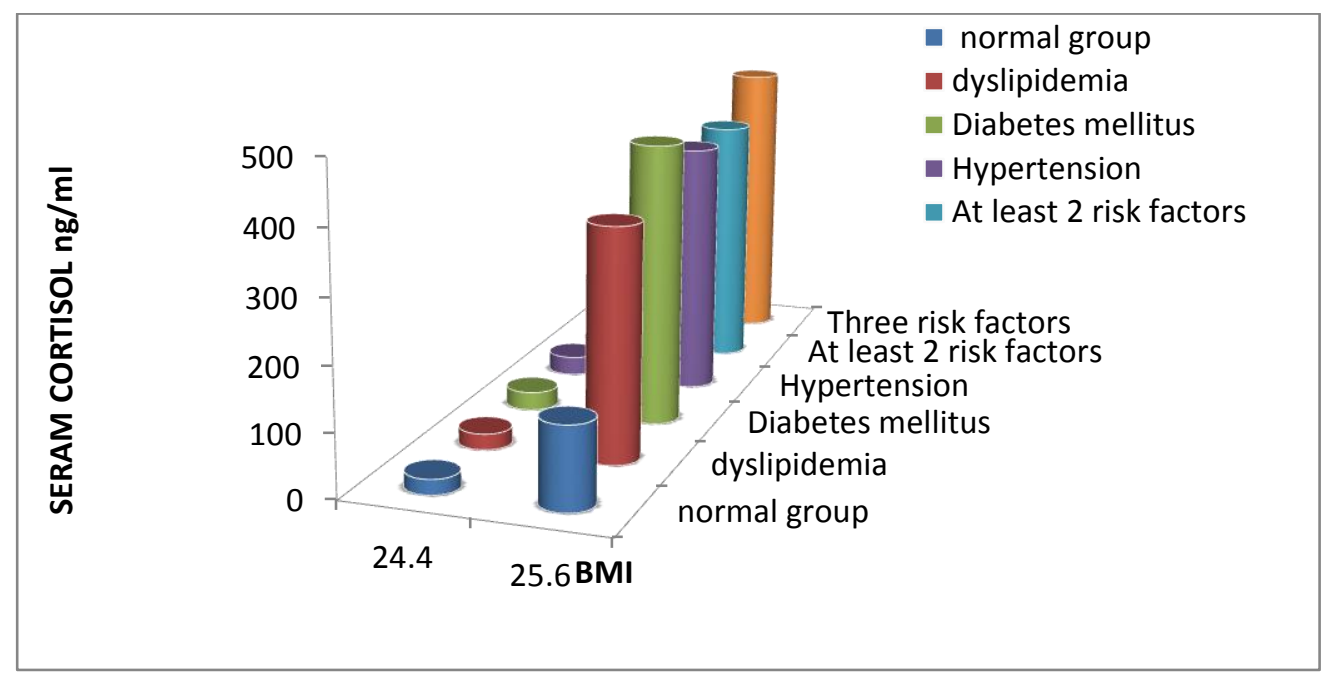

Fig. (1): mean distribution (cortisol \& BMI) in CV risk factors (dyslipidema, DM2, hypertension, At least 2 risk factors and three risk factors) patients. 


\section{Conclusion:}

In summary, there as a major association between cortisol levels, obese, and chronic diseases. These conclusions promote the hypothesis that the opposing effect of adiposity on the chronic diseases might be mediated by cortisol. This association could cause early development of cardiovascular diseases even in males.

\section{References}

[1] Visscher, TL. S.; Rissanen A; Seidell, J. C. 2004. Obesity and unhealthy life-years in adult Finns: An empirical approach. Arch Intern Med;16(4):1413-20.

[2] WHO Expert Consultation. 2004. Appropriate body-mass index for Asian populations and its implications for policy and intervention strategies. Lancet;363(10):157-63.

[3] Deurenberg, P. 2001. Universal cutoff BMI points for obesity are not appropriate. Br J Nutr;85(2):135-6.

[4] Tan, CE; Ma, S; Wai, D; Chew, SK and Tai, E.S. 2004. Can we apply the National Cholesterol Education Program Adult Treatment Panel definition of the metabolic syndrome to Asians? Diabetes Care;27(1):1826.

[5]Snehalatha, C.; Viswanathan, V, and Ramachandran, A. 2003. Cutoff values for normal anthropometric variables in asian Indian adults. Diabetes Care;26(1):380-4.

[6] Examination Committee of Criteria for 'Obesity Disease' in Japan, 2002. Japan Society for the Study of Obesity. New criteria for 'obesity disease' in Japan. Circ J;66:1:98792.

[7] Park, Y. M.; Kwon, H. S. and Lim, S. Y. 2011. Optimal waist circumference cutoff value reflecting insulin resistance as a diagnostic criterion of metabolic syndrome in a nondiabetic Korean population aged
40 years and over the Chngju Metabolic Disease Cohort (CMC) Study. Am J Clin Nutr July 94 ( 1): 34-39

[8] Bjorntorp, P. 2001. Do stress reactions cause abdominal obesity and comorbidities? Obesity Reviews, 2(2): 73-86

[9] Walker BR, Soderberg S, Lindahl B \& Olsson T. 2000:Independenteffects of obesity and cortisol in predicting cardiovascular risk factors in men and women. Journal of Internal Medicine. 247(2): 198-204

[10] Reynolds, R. M.; Syddall, H. E.; Walker, B. R.; Wood, P. J. and Phillips, D. I. W. 2003. Predicting cardiovascular risk factors from plasma cortisolmeasured during oral glucose tolerance tests. Metabolism: Clinical and Experimental 52(2): 524-527

[11] Grundy, S. M. Metabolic syndrome pandemic. 2008. Arterioscler Thromb Vasc Biol;28(6):29-36

[12] Duvnjak. L; Duvnjak, M. 2009. The metabolic syndrome - an ongoing story. J Physiol Pharmacol; 60(2):19-24.

[13] Ashwell, M.; Cole, T. G.; and Dixon, A. K. 2006. New insight into the anthropometric classification of fat distribution shown by computed tomography . BMJ . 12(2):245-251

[14] Frier, B. M; Truswell, A. S; Sheperd, J; Delogy, A; Jun, g R. 1999. Diabetes mellitus and nutritional metabolic disorder. In: Davidson Am J Med; 107(165): 1825

[15] Truswell, S. 1992. ABC of nutrition. $2^{\text {nd }}$ edition. P.55.

[16] Jung, R. T. 1997. Obesity and nutritional factor in pathogenesis of non-insulin dependant diabetes mellitus, section 4, chapter 19, In: Text book of diabetes ; pickup J.C. and William G. $; 2^{\text {nd }}$ ed. Vol. 1 . Blackwell science Itd. PP : 19.1 
[17] National Committee on the Prevention, 2003. Detection, Evaluation, and Treatment of High Blood Pressure (JNC7): resetting the hypertension sails. Hypertension; 41(9): 178-91.

[18] Expert Panel on the Detection, 2001. Evaluation, and Treatment of High Blood Cholesterol in Adults. Executive summary of the third report ofn the National Cholesterol Education Program (NCEP) Expert Panel on Detection, Evaluation, And Treatment of High Blood Cholesterol in Adults (Adults Treatment Panel III). JAMA;285(19):2486-97.

[19] Ito, H.; Nakasuga, K. and Ohshima, A. 2003. Detection of cardiovascular risk factors by indices of obesity obtained from anthropometry and dual-energy X-ray sorptionmetry in Japanese individuals. Int J Obes Relat MetabDisord;27(2):232-7.

[20] Expert Committee on the Diagnosis and Classification of Diabetes Mellitus. 2003. Report of the expert committee on the diagnosis and classification of diabetes mellitus. Diabetes Care;26(5): 20-21 .
[21] DRG International Inc 2006 :cortisol, 1-11.

[22] TOOL, E.2015 Measurement and assessment of overweight and obesity - ADULTS.

[23] The State of Obesity: 2015 Better Policies for a Healthier America. review

[24] Filipovsky, J and Ducimetiere, P. 1996. The relationship of blood pressure with glucose, insulin, heart rate, free fatty acids and plasma cortisol levels according to the degree of obesity in middle-aged men. J Hypertens.; 14(1):229 -235.

[25] Litchfield, W. R. and Hunt, S. C. 1998. Increased urinary cortisol: apotential intermediate phenotype of essential hypertension. Hypertension. 31(2):569-574.

[26] Kerstin, M and Baerbel, D. 2006. Cortisol correlates with metabolic disturbances in a population Study of type 2 diabetic patients. 154(1): $325-$ 331.

[27] Sadiqa, B. S. and Masood, A. Q. 2012. Association of Aldosterone and Cortisol with Cardiovascular Risk Factors in Prehypertension Stage. 906327, 8 pages. 


\section{ارتباط الكورتيزول و كتلة الجسم للمرضى المتزايده بالامراض المزمنة و امراض الاوعية القلبية المبكر}

مريم عبد الغفور احمد

وفاء شمخي الزهيري

اخلاص عبد الله حسن

قسم الكيمباء،كلية العلوم، جامعة ديالى، بعقوبة،ديالى،العر اق

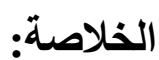

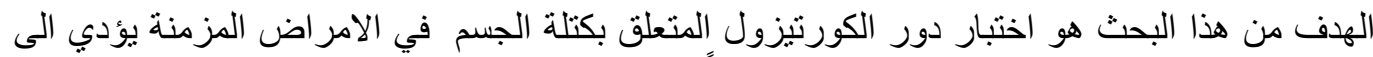

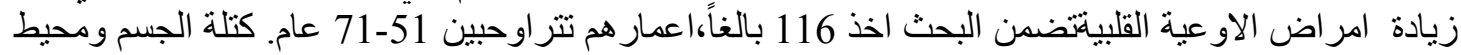

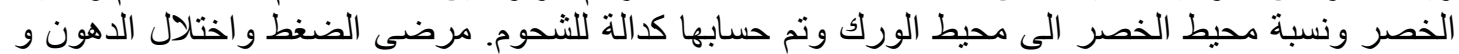

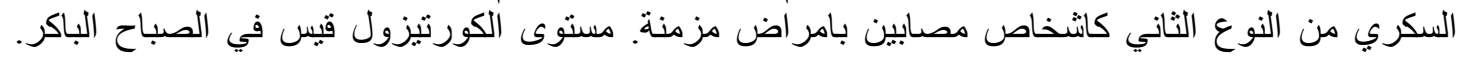

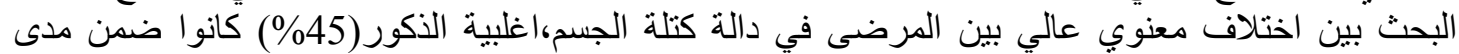

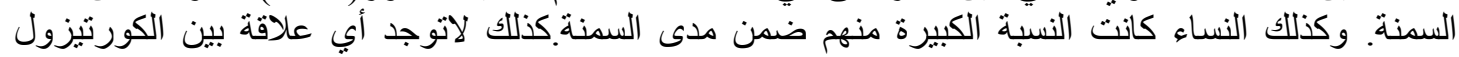

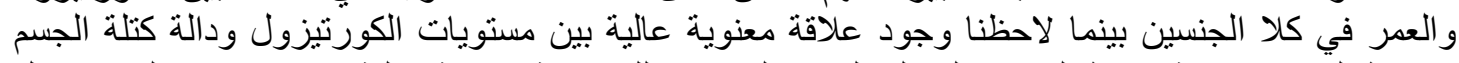

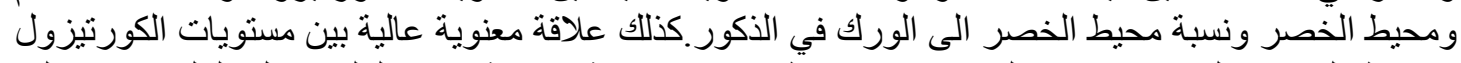

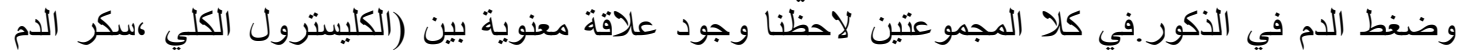

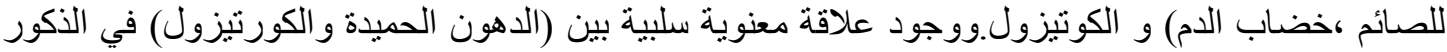

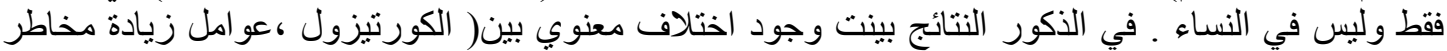

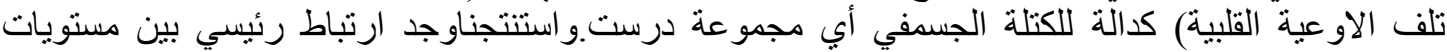

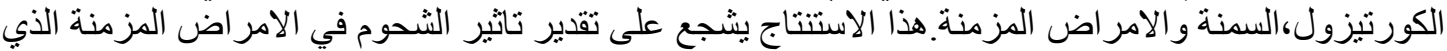

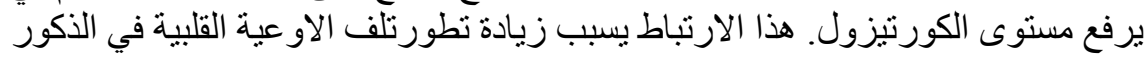

الكلمات المفتاحية : الكورتيزول، دالة كتلة الجسم ،الامر اض المزمنة ، تلف الاو عية القلبية. 